\title{
REPRESENTATION OF GRAPHICAL IMAGES FOR THE VISUALLY IMPAIRED
}

\author{
KONECKI, M. \& SUNNES, M.
}

Abstract: The visually impaired have been included in computer industry from the time it began to be popular among wider user population. Various text-to-speech synthesizers have been developed and used as a viable aiding technology that has enabled the visually impaired to use computers, to read various text materials, and to get information quicker and easier. The same technology has been used to enable the visually impaired to work as professional programmers and other computer experts. The inclusion of graphical user interfaces into broad computer usage has made using computers increasingly difficult for the visually impaired. Existing aiding technology has not been able to interpret graphical elements and overall context of the screen real estate. As a response, different solutions for representation of graphical images have emerged. In this paper, an overview of different technology used to represent graphical images is given, along with the future research directions.

Key words: visually impaired, aiding technology, graphical images, representation
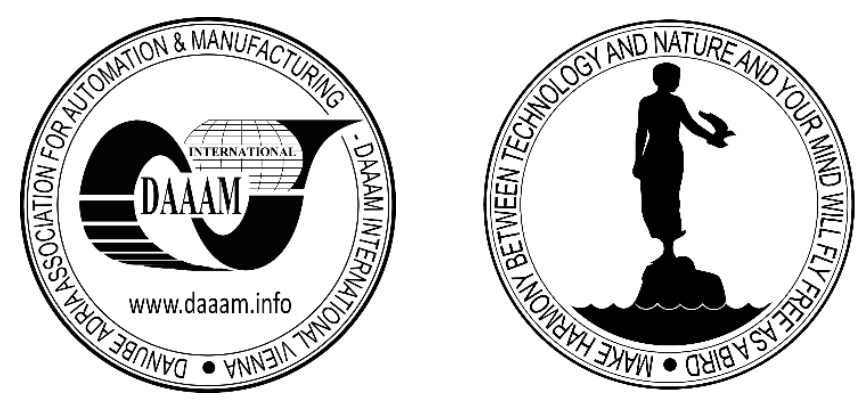

Authors' data: Dr. Sc. Konecki, M[ario]*; Sunnes, M[arshall]**, *University of Zagreb, Faculty of Organization and Informatics, Pavlinska 2, 42000 Varazdin, Croatia, **New York University, The Moses Center for Students with Disabilities, 726 Broadway, New York, NY 10003-6806, mario.konecki@foi.hr, ms9513@nyu.edu

This Publication has to be referred as: Konecki, M[ario] \& Sunnes, M[arshall] (2016). Representation of Graphical Images for the Visually Impaired, Chapter 11 in DAAAM International Scientific Book 2016, pp.113-120, B. Katalinic (Ed.), Published by DAAAM International, ISBN 978-3-902734-09-9, ISSN 1726-9687, Vienna, Austria

DOI: 10.2507/daaam.scibook.2016.11 
Konecki, M. \& Sunnes, M.: Representation of Graphical Images for the Visually Im...

\section{Introduction}

There are 345 millions of visually impaired people in the world and 45 millions of visually impaired people are blind (Bar-Cohen, 2009). The visually impaired have been a part of computer and digital revolution since its very beginning. The visually impaired have been able to use computers by using various text-to-speech synthesizers that were used as a viable aiding technology. Some of more known text-to-speech synthesizers are (Konecki, 2012; Brown, Jay, Chen \& Harper, 2012):

- JAWS

- HAL Screen Reader

- COBRA

- Window Eyes

- Easy Web Browsing

- NVDA

- VoiceOver

Use of the aforementioned text-to-speech synthesizers has enabled the visually impaired to perform complex computing tasks, including computer programming. However, the introduction of graphical user interfaces has left the visually impaired struggling with new and unresolved issues such as the inability of aiding tools to describe images or context of the screen real estate, and the need to remember rather large number of details that have emerged from graphical interfaces concept. The use of computers has remained an interest of the visually impaired as well as professional careers in programming (Alexander, 1998). Programming has also been recognized as potentially promising career opportunity for the visually impaired ("European Labour Market Report", 2004; "The employment of blind and partially-sighted persons in Italy: A challenging issue in a changing economy and society", 2016). All this however did not solve the problems that graphical user interfaces have brought in the area of education and professional work of visually impaired computer users and professionals. A particular set of problems has emerged in the area of programming education of the visually impaired. Since teaching and learning programming can be quite challenging for the general student population (Konecki, 2014a; Konecki, 2015) it is even more difficult for visually impaired students to deal with programming. The visual nature of programming development environments has made things even harder for all visually impaired students. As a result some efforts have been invested in creating different aiding tools in the area of programming education (Sanchez \& Aguayo, 2005; Smith, Francioni \& Matzek, 2000; Stefik, Haywood, Mansoor, Dunda \& Garcia, 2009; Stefik, Alexander, Patterson \& Brown, 2007; Konecki, 2014b):

- APL (Audio based Programming Language) which is as an audio-based educational tool for teaching the visually impaired about the basic programming concepts

- Javaspeak tool which is designed to describe the program code syntax and organization by usage of audio output

- SODBeans (the Sonified Omniscient Debugger in Netbeans) which includes its own compiler/debugger with added audio features

- WAD (Wicked Audio Debugger) is a special debugger developed for Visual Studio that incorporates audio features 
- GUIDL (Graphical User Interface Description Language) is a special system with its own GUIDL language that enables the visually impaired to create graphical user interfaces as a part of overall software development

Graphical user interfaces have also caused problems in other areas of computer usage and as a result many different approaches and proposed technological solutions have emerged with various degrees of usability and various application domains. The overview of different methods and technology that is used to represent graphical images to the visually impaired is given and elaborated in the rest of this paper.

\section{Methods for supporting the visually impaired in perceiving graphical images}

The Internet has brought many benefits to all computer users but its graphical nature has also created a number of problems for the visually impaired. Although web pages can be very accessible and can be interpreted by various aiding tools that produce audio output based on a given web content, more than $50 \%$ of web pages are partially or completely inaccessible to the visually impaired (Sullivan \& Matson, 2000). Two main problems can be identified when talking about visually impaired computer users: reading large amounts of text, and understanding graphical computer images. Regarding reading of text and images different solutions have emerged. One option is to prepare text in braille as a hardcopy and to prepare a special tactile hardcopy images that are created on a special paper. There are a number of different methods for creating static tactile graphics (Way \& Barner, 1997a):

- Raised-Line Drawing Boards

- Tactile-Experience Pictures

- Buildup Displays

- Embossed Paper Displays

- Braille Graphics

- Vacuum-Forming Method (thermoforming)

- Microcapsule Paper (swell paper)

- Other Methods (relief maps, cork maps and graphs, nonfigurative pictures, sewingmachine diagrams, embossed aluminum-foil displays, movable-parts displays, flannel-board diagrams, magnetic-board diagrams, electroforming processing, nyloprint, silk screening, the solid-dot process, foam-ink printing, storm relief printing, and screen drawings)

The most common methods for producing tactile images are swell paper, thermoform and braille embossers (Zeng \& Weber, 2011). This solution has been especially recognized for educational purpose, however it requires great effort (Way \& Barner, 1997a) and materials that are prepared in this way require rather large amount of storage space to archive this kind of reading material. It is also important to mention is that the process of transforming images into their tactile representations requires alterations of images that will hide details that are not important and that will highlight important segments. This process can be time consuming although some efforts to automate this process have been done (Ladner et al., 2005; Jayant et al., 2007). This alteration of images is necessary because touch has lower resolution that the sight and touch sensibility also decreases with time. 
Konecki, M. \& Sunnes, M.: Representation of Graphical Images for the Visually Im...

Another solution that has been proposed, based on the development of new technological possibilities, was refreshable braille displays (Chakraborti et al., 2012). These displays have enabled the visually impaired to read braille text but they were confined to reading small portions of text at a time since braille displays were limited in their size. Refreshable braille displays consist of a series of pins that can be lowered or elevated in such a way that enables them to form braille characters. This solution was more convenient because it required no physical storage space but it did not provide a possibility to present a larger amount of text at once. As time passed more dense pins on refreshable braille displays were produced and number of braille characters has increased. In order to develop refreshable braille displays various actuators and mechanisms have been used, such as (Bar-Cohen, 2009):

- Electromagnetic

- Piezoelectric

- Thermal

- Pneumatic

- Shape memory alloys

- Electroactive polymer materials

Different electroactive polymer materials such as conducting polymer, piezoelectric polymer, dielectric elastomers and ionic polymer metal composite (Chakraborti et al., 2012) have been especially suitable for presentation of larger amount of text at once by making actuators denser (Bar-Cohen, 2009). These materials provide lightweight, inexpensive, energy efficient, and generally exhibit fast responses (Chakraborti et al., 2012). Regarding graphical images representation different solutions have also been proposed, such as:

- Audiograph (Alty \& Rigas, 1998)

- IC2D (Kamel \& Landay, 1999)

- Tactile web panel (Rotard, Taras \& Ertl, 2008)

- Cat (Ebina, Igi, Miyake \& Takahashi, 1998)

- Three-Dimensional Tactile Display developed by Shinohara et al. (Shinohara, Shimizu \& Mochizuki, 1998)

- Virtual Tactile Display (Maucher, Schemmel \& Meier, 2000)

- Tactos device (Gapenne, Rovira, Ali Ammar \& Lenay, 2003)

- BrailleDis 9000 (Völkel, Weber \& Baumann, 2008)

- MaskGen system (Petit, Dufresne, Levesque, Hayward \& Trudeau, 2008)

Audiograph uses different sounds and pitches to represent images. IC2D also provides sonification of graphical information. Research has however shown that audio output is not in many cases sufficient to adequately describe an image (Way \& Barner, 1997b). Tactile web panel is used to try to represent web content by a series of lowered or elevated pins and in this way it resembles multiline refreshable braille displays with the difference that there are no groups of pins that would represent particular braille character but rather all pins have equal space between them. The very idea of replacing visual displays with tactile displays has been introduced by Noisezewski (Shinohara, Shimizu \& Mochizuki, 1998). Cat, Three-Dimensional Tactile Display, Virtual Tactile Display and Tactos device are all used to represent graphical image in a tactile way by using appropriate tactile display. MaskGen system enables inclusion of audio 
description of certain tactile parts of displayed image. In order to enable the visually impaired to draw images and play computer games an interactive tactile system has been proposed with possibility to play some simple games (Watanabe, Kobayashi, Ono \& Yokoyama, 2006). One of the problems that was encountered with this kind of system was its low resolution (low density of the pins) and problems with precise drawing of lines and circles were also detected. Along with various tactile displays that use pins to show an image, solutions that include haptic feedback and representation of images have also been proposed (Toennies, Burgner, Withrow \& Webster, 2011). In order to provide the visually impaired with a viable solution for reading various materials several requirements have to be met. These requirements include (Runyan \& Blazie, 2010):

- Affordable, compact, battery powered, single braille line devices for early education

- Multiple line and full page braille displays

- Full page tactile graphics displays

- Image reading systems such as the Optacon (Goldish \& Taylor, 1974) or TVSS (Shinohara, Shimizu \& Mochizuki, 1998)

- Vision substitution arrays

- Small displays for watches, calculators, and cellphones

- Tactile virtual reality systems

The price and compact design have been two of the biggest obstacles to commercialization of many proposed tactile display prototypes (Vidal-Verdu \& Hafez, 2007). In order to provide a usable solution a complete reading system should enable:

- Image capture (scanning of text and images)

- Converting of scanned text into digital text using OCR technology

- Converting digital text into braille information

- Displaying braille characters and tactile images with added support for audio output

\section{Conclusion}

Many benefits of computer usage for the visually impaired have been greatly influenced by introduction of graphical user interfaces in the world of computers. Existing technology experienced problems with providing adequate representation of graphical images and of overall context of screen real estate. Over the years many different solutions have emerged that were developed to enable the visually impaired to perceive graphical images as well as textual materials. Many solutions that have been developed and are widely used to this day include different methods for creating tactile graphics on a special paper. In this way the whole books and other reading materials are made available in hardcopy form and as such are provided to visually impaired users. This kind of approach requires simplification of images and careful selection of different textures in order for the visually impaired to be able to understand the image and difference between surfaces that are next to each other. Books and materials made in this way required a lot of effort and they also occupy a lot of space. In order to provide a more dynamic solution various forms of refreshable braille displays have been proposed. As time has passed and technology has advanced, these displays have become denser which means that they included more pins on the same 
Konecki, M. \& Sunnes, M.: Representation of Graphical Images for the Visually Im...

surface size which has enabled representations of not just braille characters but also simplified graphical images. Different forms of haptic feedback and sonification have also been used to try to represent certain graphical elements. The biggest challenges for aiding technology has always been how to make a simple, compact and affordable refreshable braille display that would be accessible to wide categories of users.

Based on the aforementioned technology and anticipation of future technological advances the next step in making graphical images and texts available to the visually impaired as well as in making computer usage easier and more useful for the visually impaired will be creation of refreshable braille displays that will be aided by haptic and audio feedback. This kind of displays will provide an interactive experience through interactive pins that will be developed as sensors that will be able to provide a mean of controlling computer actions. An example of using this kind of system would be to have a tactile map of the country with the ability to point out the area of interest and getting audio feedback about the weather in that particular area. Further research about means of providing the visually impaired with solutions for graphical images representation and easier computer usage as well as development of new models of technological aiding solutions will be a part of future research.

\section{References}

Alexander, S. (1998). Blind Programmers Face An Uncertain Future. ComputerWorld, Vol. 32, No.44, pp. 86-87

Alty, J. L., \& Rigas, D. I. (1998). Communicating graphical information to blind users using music: the role of context. In Proceedings of the SIGCHI conference on Human factors in computing systems, pp. 574-581, ACM Press/Addison-Wesley Publishing Co

Bar-Cohen, Y. (2009). Electroactive polymers for refreshable Braille displays. SPIE Newsroom, 11

Brown, A., Jay, C., Chen, A. Q., \& Harper, S. (2012). The uptake of Web 2.0 technologies, and its impact on visually disabled users. Universal Access in the Information Society, Vol. 11, No. 2, pp. 185-199

Chakraborti, P., Toprakci, H. K., Yang, P., Di Spigna, N., Franzon, P., \& Ghosh, T. (2012). A compact dielectric elastomer tubular actuator for refreshable Braille displays. Sensors and Actuators A: Physical, 179, pp. 151-157

Ebina, T., Igi, S., Miyake, T., \& Takahashi, H. (1998). Graph access system for the visually impaired. In Computer Human Interaction, 1998. Proceedings. 3rd Asia Pacific, pp. 254-259, IEEE

Gapenne, O., Rovira, K., Ali Ammar, A., \& Lenay, C. (2003). Tactos: Special computer interface for the reading and writing of 2D forms in blind people. Universal Access in HCI, Inclusive Design in the Information Society, 10, pp. 1270-1274

Goldish, L. H., \& Taylor, H. E. (1974). The Optacon: A Valuable Device for Blind Persons. New Outlook for the Blind, Vol. 68, No. 2, pp. 49-56

Jayant, C., Renzelmann, M., Wen, D., Krisnandi, S., Ladner, R., \& Comden, D. (2007). Automated tactile graphics translation: in the field. In Proceedings of the 9th 
international ACM SIGACCESS conference on Computers and accessibility, pp. 7582, ACM

Kamel, H. M., \& Landay, J. A. (1999). The integrated communication 2 draw (IC2D): a drawing program for the visually impaired. In CHI'99 Extended Abstracts on Human Factors in Computing Systems, pp. 222-223, ACM

Kamel, H. M., \& Landay, J. A. (2002). Sketching images eyes-free: a grid-based dynamic drawing tool for the blind. In Proceedings of the fifth international ACM conference on Assistive technologies, pp. 33-40, ACM

Konecki, M. (2012). A new approach towards visual programming for the blinds. In Proceedings of the 35th MIPRO International Convention on Computers in Technical Systems, pp. 1076-1081, IEEE

Konecki, M. (2014a). Problems in programming education and means of their improvement. DAAAM International Scientific Book 2014, pp. 459-470

Konecki, M. (2014b). GUIDL as an aiding technology in programming education of visually impaired. Journal of Computers, Vol. 9, No. 12, pp. 2816-2821

Konecki, M. (2015). Improving students' focus in introductory programming courses. DAAAM International Scientific Book 2015, pp. 165-172

Ladner, R. E., Ivory, M. Y., Rao, R., Burgstahler, S., Comden, D., Hahn, S., ... \& Martin, A. (2005). Automating tactile graphics translation. In Proceedings of the 7th international ACM SIGACCESS conference on Computers and accessibility, pp. 150157, ACM

Maucher, T., Schemmel, J. \& Meier, K. (2000). The Heidelberg Tactile Vision Substitution System. In International Conference on Computers Helping People with Special Needs (ICCHP2000). Karlsruhe, Germany

Petit, G., Dufresne, A., Levesque, V., Hayward, V., \& Trudeau, N. (2008). Refreshable tactile graphics applied to schoolbook illustrations for students with visual impairment. In Proceedings of the 10th international ACM SIGACCESS conference on Computers and accessibility, pp. 89-96, ACM

Rotard, M., Taras, C., \& Ertl, T. (2008). Tactile web browsing for blind people. Multimedia Tools and Applications, Vol. 37, No. 1, pp. 53-69

Sánchez, J., \& Aguayo, F. (2005). Blind learners programming through audio. In CHI'05 extended abstracts on Human factors in computing systems, pp. 1769-1772, ACM

Runyan, N., \& Blazie, D. (2010). EAP actuators aid the quest for the' Holy Braille' of tactile displays. In SPIE Smart Structures and Materials+ Nondestructive Evaluation and Health Monitoring, pp. 764207-764207, International Society for Optics and Photonics

Shinohara, M., Shimizu, Y., \& Mochizuki, A. (1998). Three-dimensional tactile display for the blind. IEEE Transactions on Rehabilitation Engineering, Vol. 6, No. 3, pp. 249-256

Smith, A. C., Francioni, J. M., \& Matzek, S. D. (2000). A Java programming tool for students with visual disabilities. In Proceedings of the fourth international ACM conference on Assistive technologies, pp. 142-148, ACM 
Konecki, M. \& Sunnes, M.: Representation of Graphical Images for the Visually Im...

Stefik, A., Alexander, R., Patterson, R., \& Brown, J. (2007). WAD: A feasibility study using the wicked audio debugger. In 15th IEEE International Conference on Program Comprehension (ICPC'07), pp. 69-80, IEEE

Stefik, A., Haywood, A., Mansoor, S., Dunda, B., \& Garcia, D. (2009). Sodbeans. In IEEE 17th International Conference on Program Comprehension (ICPC'09), pp. 293294, IEEE

Sullivan, T., \& Matson, R. (2000). Barriers to use: usability and content accessibility on the Web's most popular sites. In Proceedings on the 2000 conference on Universal Usability, pp. 139-144, ACM

Toennies, J. L., Burgner, J., Withrow, T. J., \& Webster, R. J. (2011). Toward haptic/aural touchscreen display of graphical mathematics for the education of blind students. In World Haptics Conference (WHC), pp. 373-378, IEEE

Vidal-Verdu, F., \& Hafez, M. (2007). Graphical tactile displays for visually-impaired people. IEEE Transactions on neural systems and rehabilitation engineering, Vol. 15, No. 1, pp. 119-130

Völkel, T., Weber, G., \& Baumann, U. (2008). Tactile graphics revised: the novel brailledis 9000 pin-matrix device with multitouch input. In International Conference on Computers for Handicapped Persons, pp. 835-842, Springer Berlin Heidelberg

Watanabe, T., Kobayashi, M., Ono, S., \& Yokoyama, K. (2006). Practical use of interactive tactile graphic display system at a school for the blind. In Proc. Fourth International Conference on Multimedia and Information and Communication Technologies in Education (m-ICTE), pp. 1111-1115

Way, T. P., \& Barner, K. E. (1997a). Automatic visual to tactile translation. I. Human factors, access methods and image manipulation. IEEE Transactions on Rehabilitation Engineering, Vol. 5, No. 1, pp. 81-94

Way, T. P., \& Barner, K. E. (1997b). Automatic visual to tactile translation. II. Evaluation of the TACTile image creation system. IEEE Transactions on Rehabilitation Engineering, Vol. 5, No. 1, pp. 95-105

Zeng, L., \& Weber, G. (2011). Accessible maps for the visually impaired. In Proceedings of IFIP INTERACT 2011 Workshop on ADDW, CEUR, Vol. 792, pp. 5460

bfiSteiermark (2004). "European Labour Market Report", available at http://eurochance.brailcom.org/download/labour-market-report.pdf, accessed: 25th August 2016

"The employment of blind and partially-sighted persons in Italy: A challenging issue in a changing economy and society", available at http://www.euroblind.org/media/employment/employ ment_Italy.doc, accessed: 25th August 2016 